\title{
Ocorrência de Vibrio parahaemolyticus e Salmonella spp. em "sashimis" comercializados em restaurantes no município do Rio de Janeiro
}

\section{Occurrence of Vibrio parahaemolyticus and Salmonella spp. in sashimi commercialized in restaurants at the city Rio de Janeiro}

\author{
Lícia Cristina Miranda Malavota, ${ }^{*}$ Juliana de Castro Beltrão da Costa, ${ }^{* *}$ Marcela Fonseca Jardim, ${ }^{* \star}$ \\ Luiz Antônio Trindade de Oliveira, ${ }^{* * *}$ Robson Maia Franco, ${ }^{* *}$ Valéria Moura de Oliveira****
}

\begin{abstract}
Resumo
Visando conhecer a segurança do produto "sashimi" de salmão fornecido em restaurantes, e dos riscos potenciais ao consumidor, a pesquisa objetivou avaliar a ocorrência de Vibrio parahaemolyticus e de Salmonella spp na matéria-prima, no produto final antes de sua exposição à venda e após sua exposição ao cliente; e de Salmonella spp nas mãos dos manipuladores, em dois restaurantes (RI e RII). Os estabelecimentos foram classificados pelas diferentes condições de higiene e climatização do ambiente de manipulação, sendo RIl considerado o melhor. Foi verificada a ausência de Vibrio parahaemolyticus em $100 \%$ das amostras; presença de Salmonella spp. em $12,5 \%$ do total de amostras analisadas, sendo todas estas pertencentes a RII: $25 \%$ estava presente na mão do manipulador e $75 \%$, presente na matéria-prima e produtos finais. Através dos resultados da pesquisa pôde-se concluir que ambos os estabelecimentos estavam em conformidade com a RDC 12 de 2001 da ANVISA para Vibrio parahaemolyticus, mas RII enquadrou-se fora dos padrões estabelecidos quanto à presença de Salmonella spp. O resultado sugere que RII necessita da adoção eficaz de práticas higiênicosanitárias na elaboração de "sashimi" para eliminar a presença de Salmonella spp., que é um risco potencial à saúde do consumidor.
\end{abstract}

Palavras-chave: pescado, "sashimi", Vibrio parahaemolyticus, Salmonella spp.

\begin{abstract}
In order to know the quality and safety of the sashimi salmon comes in restaurants and its potential risks to the consumer, this research aimed evaluated the occurrence of Vibrio parahaemolyticus and Salmonella in raw material, on the final product before its exposure to sales and after exposure to the client and Salmonella spp in the hands of handlers, in two restaurants (RI and RII). The difference between the places was classified by the conditions of environmental air handling and hygiene, and RII was considered the best. It was verified the absence of Vibrio parahaemolyticus in $100 \%$ of samples, the presence of Salmonella spp. in $12.5 \%$ of total samples analyzed, with absence in all samples of RI and presence in $25 \%$ of samples at RII. In this proven contamination, $25 \%$ was present in the hands of the handlers and $75 \%$ present in the raw material and finished products. Based on the results of research it was concluded that both establishments were in compliance with the legislation for the first microorganism, but RII, although had the best conditions of climate and hygiene, framed outside of the microbiological standards established by the presence of Salmonella spp. The results suggest that the establishment in violation of the law requires the efficient and effective adoption of adequate sanitary practices in preparation of sashimi to avoid the presence of Salmonella spp., which can pose a risk to consumer health.
\end{abstract}

Keywords: fish, sashimi, bacteriologic quality, Vibrio parahaemolyticus, Salmonella spp.

\section{Introdução}

A produção e o consumo de peixes e derivados têm aumentado nos últimos 20 anos, e estes alimentos já constituem a maior parte da proteína animal consumida em várias partes do mundo, segundo a "Food and Agriculture Organization" (FAO, 2003). Esse consumo está associado ao baixo teor de gordura de muitas espécies e aos efeitos dos ácidos graxos da série ômega-3 sobre doenças coronarianas em seres humanos.

* Estudante do Programa de Pós-graduação em Higiene Veterinária e Processamento Tecnológico de Produtos de Origem Animal da Faculdade de Veterinária da Universidade Federal Fluminense. Rua Vital Brazil Filho, 64. CEP 24230-340 - Niterói, RJ, Brasil. A quem enviar correspondência: liciamalavota@hotmail.com

** Acadêmica da Faculdade de Veterinária da Universidade Federal Fluminense.

*** Departamento de Tecnologia dos Alimentos, Faculdade de Veterinária, Universidade Federal Fluminense.

*** Departamento de Higiene e Saúde Pública, Universidade Federal Rural do Rio de Janeiro. BR-465, Km 7, CEP. 23890-000. Seropédica, RJ, Brasil. 
O salmão é um grande peixe da família Salmonidae, muito procurado pela sua apreciada carne rosada, peculiar aos mares e rios europeus, utilizado também em aquicultura como no norte da Noruega (Stansby, 1968).

O "sashimi" é uma iguaria da culinária do Japão primariamente consistindo de frutos do mar bem frescos, cortados em fatias finas e servidos crus (Watanabe, 2005).

O hábito de ingerir peixes, em especial crus, é de introdução recente no cardápio dos estabelecimentos de alimentos nas cidades brasileiras e vem aumentando nos últimos anos (Martins; Santos, 2006).

Segundo Jay (2005), a microbiota do pescado reflete a água onde vivem, visto que os tecidos internos de um peixe sadio são estéreis, sendo a qualidade sanitária da água de onde os animais são retirados fundamental à qualidade microbiológica do produto final. Os micro-organismos também podem ser veiculados nas várias etapas do processamento, como o descasque, a descamação, a evisceração e as demais manipulações (Andrade, 1998; Forsythe, 2002; Hobbs e Roberts, 1999).

Devido à composição e condições de higiene, transporte e armazenamento do pescado fresco, o alimento se torna vulnerável à ação de patógenos, estando amplamente associado com enfermidades de origem alimentar. O Vibrio spp. e a Salmonella spp. são exemplos destes microorganismos (Silva Junior, 2001).

A Salmonella spp. tem grande importância para a Saúde Pública, considerando-se seu caráter zoonótico e sua ampla distribuição na natureza, sendo responsável por doenças de origem alimentar em vários países, incluindo o Brasil (Taunay et al., 1996).

Segundo Jay (2005), a infecção por Salmonella spp. é causada pela ingestão de alimentos que contenham números significativos de espécies do gênero, e os sintomas consistem em náuseas, vômitos, dores abdominais, calafrios e diarreia.

Numerosos casos de gastrenterite registrados no Japão, Estados Unidos e Europa associados à ingestão de frutos do mar têm como agente causal o Vibrio parahaemolyticus. No Japão, este agente é a principal causa de enfermidades de origem alimentar (Jay, 2005), embora, no Brasil, sejam poucos os relatos sobre a ocorrência desta bactéria em alimentos comercializados no Brasil e sua incidência em casos de gastrenterites (Saavedra et al., 2004).

De acordo com a grande relevância do assunto e do patógeno em questão, Chen (2004), com o objetivo de avaliar a presença de Vibrio parahaemolyticus em atum, comparou a sazonalidade da contaminação e avaliou a sensibilidade do micro-organismo a antibióticos.

Embora um estudo feito no Japão pela "Food and Environmental Department Hygiene" (FEDH, 2000a) comprove que o "sashimi" é um alimento geralmente seguro, os dados da pesquisa comprovam que cuidados durante a elaboração do produto devem ser rigorosamente adotados. O mesmo órgão divulga dados de amostras analisadas de "sushi" e "sashimi" impróprios para o consumo em Hong Kong (FEDH, 2000b).
Herrera (2006) descreveu que alimentos à base de pescado cru oferecem riscos à saúde de quem os consome, visto que estes produtos carreiam bactérias nocivas à saúde e Silva Junior (2001) associa surtos de doenças de origem alimentar com procedimentos inadequados em uma ou mais etapas da produção dos alimentos, por descumprimento das normas de Boas Práticas de Fabricação (BPF).

Desta forma, o estudo objetivou inicialmente selecionar dois restaurantes distintos quanto à adoção das normas das BPF no que tange à estrutura física: temperatura ambiente da sala de manipulação e superfícies de manipulação dos alimentos. Posteriormente, avaliar nestes locais a ocorrência de: Vibrio parahaemolyticus e de Salmonella spp nas amostras coletadas de matéria-prima, dos "sashimis" antes e após a exposição à venda; e de Salmonella spp nas mãos dos manipuladores, comparando seus resultados bacteriológicos com a legislação vigente (Brasil, 2001).

Esta pesquisa tende a oferecer dados muito relevantes para a saúde pública, em especial, à Vigilância Sanitária do Rio de Janeiro, relativos à venda e ingestão de pescados crus contaminados.

\section{Material e métodos}

Para este estudo, foram escolhidos dois restaurantes no município do Rio de Janeiro, cuja adequação às normas sanitárias concernentes ao aspecto de edificação e instalações fossem diferentes. Neste sentido, RI foi caracterizado como "local onde as normas sanitárias não estavam integralmente atendidas — sistema de refrigeração para estocagem de matéria-prima não exclusivo para peixes, sala de manipulação dos alimentos com temperatura média de $28^{\circ} \mathrm{C}$ e placa de corte do alimento com rugosidades" - e RII foi caracterizado como "local onde as normas sanitárias estavam em conformidade - sistema de refrigeração para estocagem da matéria-prima exclusivo para peixes, sala de manipulação dos alimentos com temperatura média de $18^{\circ} \mathrm{C}$ e placa de corte do alimento lisa e lavável".

Foram coletadas assepticamente 64 amostras no total, sendo 32 de $\mathrm{RI}$ e 32 de RII, igualmente divididas em quatro grupos conforme o tipo de amostra: (A) produto in natura; (B) "sashimi" antes de sua exposição à venda; $(C)$ "sashimi" após sua exposição à venda, cujo tempo de exposição foi fixado em duas horas sob temperatura controlada de $10^{\circ} \mathrm{C}$; (D) mãos de manipuladores. A coleta deste último tipo de amostra foi realizada com zaragatoa, umedecida em solução salina peptonada $0,1 \%$. Foram acondicionadas em recipientes isotérmicos com gelo e encaminhadas ao Laboratório de Controle Microbiológico de Produtos de Origem Animal da Universidade Federal Fluminense, para realização de análises para Vibrio parahaemolyticus, e Salmonella spp.

As análises de Vibrio parahaemolyticus seguiram as determinações da Instrução Normativa № 62 (BRASIL, 2003). Para Salmonella spp., os procedimentos analíticos de isolamento adotados seguiram descrição de Pignato et al. (1995), e as provas confirmatórias também seguiram as determinações da Instrução Normativa № 62 (Brasil, 2003).

Para a identificação e isolamento de Salmonella spp., foram pesados $25 \mathrm{~g}$ de cada amostra, adicionados $225 \mathrm{~mL}$ de caldo 
base "Salmosyst", meio de pré-enriquecimento, homogeneizados por 120 segundos em "stomacher" e incubados a $37^{\circ} \mathrm{C}$ por 6 horas. Do enriquecimento foram transferidos assepticamente $10 \mathrm{~mL}$ para tubos contendo tablete de suplemento seletivo "Salmosyst", homogeneizados e incubados a $37^{\circ} \mathrm{C}$ por 18 horas. A partir de cada tubo, com auxílio de uma alça de platina estéril, retirou-se uma alçada do crescimento e estriou-se em placa de Petri com meio Rambach, que foram incubadas a $37^{\circ} \mathrm{C}$ por 24 horas. Após a leitura de cada placa, selecionaram-se três a cinco colônias típicas, as quais foram transferidas simultaneamente para tubos contendo Agar ferro três açúcares (TSI) e Agar lisina com ferro (LIA), através de picada profunda e estriamento na superfície inclinada do bisel e os tubos incubados a $37^{\circ} \mathrm{C}$ por 24 horas. A partir destes tubos, procedeu-se o esfregaço em lâmina e coloração pelo método de Gram.

Em seguida, realizou-se a prova de soroaglutinação, ressuspendendo os cultivos do TSI, em dois $\mathrm{mL}$ de solução salina $0,85 \%$ e depositando-se em lâmina de vidro uma gota do soro anti-Salmonella polivalente "O" (Probac do Brasil) e posteriormente adicionou-se uma gota da suspensão em teste, promovendo-se movimentos circulares antes da leitura em um a dois minutos.

\section{Resultados e discussão}

Para que o estudo obtivesse êxito em sua proposta, foi necessário avaliar e monitorar fatores de influência nos resultados das análises, para tornar os dados invariáveis, como o binômio tempo e temperatura na estocagem, manipulação, manutenção e exposição do alimento.

Foi verificada ausência de Vibrio parahaemolyticus em 100\% das amostras analisadas nos dois restaurantes, o que indica que os resultados estão de acordo com a legislação brasileira vigente (Brasil, 2001).

As diferentes condições higiênico-sanitárias de RI e RII não foram relevantes na obtenção destes resultados, visto que não influenciaram nos mesmos. Embora houvesse diferença na climatização ambiente e nas condições de higiene do local durante a manipulação do alimento, estes fatores não determinaram diferenças nos resultados obtidos para $V$. parahaemolyticus, visto que a mais provável razão da presença deste patógeno nos alimentos seria uma contaminação oriunda da aquisição da matéria-prima, e não uma contaminação subsequente à manipulação do produto frente às condições a que estavam expostos.

A patogenicidade deste micro-organismo é discutida em documentos publicados pela FAO (2003), onde estão descritos que os Vibrio parahaemolyticus designados como patogênicos nem sempre o são, pois na maioria das espécies selvagens faltam os fatores de colonização necessários para a aderência e penetração, toxinas apropriadas ou outros determinantes da virulência necessários para causar a doença.

Entretanto, segundo Jay (2005), os dados desta pesquisa são relevantes, pois a presença des- te patógeno nos alimentos, principalmente naqueles consumidos crus, em concentrações superiores a 5,0 $\log _{10}$ levaria a uma intoxicação no consumidor, aumentando os custos públicos com os serviços de saúde.

Na pesquisa de V.parahaemolyticus em 20 amostras de "sashimis" comercializados em São Paulo, realizada por Santos (2006), os resultados foram semelhantes aos obtidos no presente estudo e, portanto, o produto foi considerado próprio para o consumo.

Estes resultados também estão de acordo com os obtidos por Herrera et al. (2006), num estudo sobre micro-organismos patogênicos, incluindo $V$. parahaemolyticus, em peixes marinhos frescos comercializados na Espanha, onde $100 \%$ das amostras foram negativas para esta bactéria.

Os resultados obtidos por Chen (2004) foram similares em pesquisa realizada com atum, em São Paulo, na qual constatou que apenas três, das 112 amostras analisadas, continham esse patógeno, obtendo, assim, baixos valores de NMP, comparando-se aos limites estabelecidos na legislação (Brasil, 2001).

Entretanto, comparando os dados do presente estudo com os resultados obtidos por Martins (2006), observam-se significativas diferenças, já que o $\mathrm{V}$. parahaemolyticus foi isolado em $35 \%$ das 20 amostras analisadas em "sushi" e "sashimi", sendo este um dado muito importante quanto aos aspectos relacionados com a saúde pública.

$\mathrm{Na}$ pesquisa sobre ocorrência de $V$. parahaemolyticus em mexilhões do litoral de Santa Catarina feita por Archer et al. (1994), em 52,5\% das amostras foi constatada a presença da bactéria, com níveis de contaminação entre <3 e 93 NMP/ $\mathrm{g}$, embora nenhuma dessas culturas tenha apresentado positividade para o teste de Kanagawa, que caracteriza sua virulência.

Em estudo semelhante com 50 amostras de mexilhões e ostras comercializados na cidade de Niterói, Pereira et al. (2004) isolaram 141 cepas da espécie, mas nenhuma destas culturas foi positiva para o teste de Kanagawa.

$\mathrm{Na}$ Tabela 1 podem ser observados os percentuais de amostras com concentração bacteriana ou presença de bactéria em não conformidade aos limites toleráveis (Brasil, 2001; Jay, 2005) nas 64 amostras divididas como: matériaprima/peixe íntegro (amostra A), "sashimi" antes da exposição ao consumidor (amostra B); "sashimi" depois da exposição à venda após duas horas a $10^{\circ} \mathrm{C}$ (amostra $\mathrm{C}$ ); e mãos de manipuladores (amostra D), os quais diferiram para os estabelecimentos.

Tabela 1: Percentual de amostras com concentração bacteriana ou presença de bactéria em não conformidade aos limites toleráveis (Brasil, 2001; Jay, 2005).

\begin{tabular}{l|c|c|c}
\hline Micro-organismos analisados & $\begin{array}{c}\text { Percentual de } \\
\text { amostras fora dos } \\
\text { padrões em RI }\end{array}$ & $\begin{array}{c}\text { Percentual de } \\
\text { amostras fora dos } \\
\text { padrões em RII }\end{array}$ & $\begin{array}{c}\text { Percentual total de } \\
\text { amostras fora dos } \\
\text { padrões (RI e RII) }\end{array}$ \\
\hline NMP Vibrio parahaemolyticus & 0 & 0 & 0 \\
\hline $\begin{array}{l}\text { Isolamento e identificação de } \\
\text { Salmonella spp. }\end{array}$ & 0 & 25 & 12,5 \\
\hline
\end{tabular}


Pôde-se constatar a presença de Salmonella spp. em oito das 64 amostras de alimentos analisadas (12,5\%). Em RI, $100 \%$ das amostras testadas foram negativas para esta bactéria. Das 32 amostras testadas em RII, 25\% das amostras continham Salmonella spp. Na análise dos resultados totais, constatou-se que a presença deste micro-organismo em $12,5 \%$ das amostras as tornou impróprias para o consumo (Brasil, 2001).

O fato de as edificações e instalações de RII contarem com características como câmaras frigoríficas exclusivas para peixes e climatização do ambiente de manipulação, levou a uma falsa hipótese de que seriam obtidos melhores resultados bacteriológicos nas análises quando fossem confrontados com RI. Entretanto, esta pré-suposição não foi confirmada quando as análises foram realizadas, pois melhores resultados foram obtidos em $\mathrm{RI}$ para pesquisa de Salmonella spp.

Esses resultados podem ser explicados pela ocorrência de falhas durante o processo de elaboração do produto, o que pode ser independente das características físicas do estabelecimento, tais como: a aquisição de matéria-prima sem devido controle de suas qualidades microbiológica e físico-química e de sua temperatura de transporte; o tempo excessivo gasto na manipulação do produto durante a elaboração; as condições precárias de higiene durante a manipulação; a existência de portadores assintomáticos de Salmonella spp. Este tipo de falha pode ser minimizado ou eliminado com educação sanitária e treinamentos sobre a segurança dos alimentos, que embora existissem no local, pôde-se constatar que houve falha na execução das orientações.

$\mathrm{Na}$ Tabela 2, podem ser observados as quantidades e percentuais em não conformidade (Brasil, 2001; Jay, 2005) devido à contaminação por Salmonella spp. por cada tipo de amostra em RII.

Tabela 2: Quantidade e percentual em não conformidade (Brasil, 2001; Jay, 2005) devido à contaminação por Salmonella spp. por cada tipo de amostra em RII

\begin{tabular}{c|c|c|c|c}
\hline Amostras & A & B & C & D \\
\hline Quantidade & 2 & 3 & 1 & 2 \\
\hline Percentual & 25 & 37,5 & 12,5 & 25 \\
\hline
\end{tabular}

A - MATÉRIA-PRIMA (peixe íntegro); B - SASHIMI PREPARADO (mantido em geladeira a $4^{\circ} \mathrm{C}$ antes da exposição à venda); $\mathrm{C}$ - SASHIMI DEPOIS DA EXPOSIÇÃO (exposto à venda a $10^{\circ} \mathrm{C}$ por duas horas); D - MÃO DE MANIPULADOR

O resultado obtido no presente estudo é de grande relevância, devido ao alto grau de patogenicidade da Salmonella spp., que levou a Legislação a exigir sua ausência em 25 gramas de amostra analisada para que o alimento seja considerado próprio para o consumo (Brasil, 2001).

Os dados deste estudo sugerem que a contaminação por Salmonella spp. pode ter origem na matéria-prima $(A)$, o que teria como consequência a presença da bactéria também nas amostras de produto final antes e depois da exposição ao consumo ( $B$ e $C$, respectivamente) pois ambas são oriundas de "A". O mesmo raciocínio se aplica para explicar a origem da contaminação das mãos do manipulador (D), pois a superfície em questão entra em contato direto com o alimento já contaminado "A". A contaminação do alimento, como consequência de contaminações cruzadas, já foi proposta por Forsythe (2002), Jay (2005) e Silva Junior (2001).

Resultados similares foram encontrados por Santos (2006) em pesquisa com 20 amostras de "sashimis" comercializados em São Paulo, onde constatou a presença de Salmonella spp. em 15\% dos alimentos, que foram também considerados impróprios para o consumo.

Resultados mais satisfatórios do que os da atual pesquisa foram divulgados num estudo com "sashimis", desenvolvido pela Food and Environmental Hygiene Department (FEDH, 2000b), no qual micro-organismos patogênicos foram encontrados em apenas 0,26\% das 906 amostras analisadas, sendo que Salmonella spp. e Vibrio parahaemolyticus foram encontrados apenas em duas amostras dos produtos separadamente.

Martins (2006), testando o mesmo produto, observou ausência de Salmonella spp. em 100\% das amostras testadas. Resultado igual ao obtido por Adesiyun (1993), que constatou ausência desta bactéria em 61 amostras de peixes analisadas. Schulz et al. (2003) também observaram ausência deste patógeno analisando amostras de "sushi" e de peixes crus, o que representa bons resultados aos consumidores deste tipo de alimento.

Os dados do presente estudo foram mais satisfatórios do que os obtidos numa pesquisa conduzida por Menezes et al. (2006) em Fortaleza, Ceará, na qual foi constatada uma ocorrência alarmante de $50 \%$ de Salmonella spp. em "sashimi" e que mereceu especial atenção dos órgãos de saúde pública.

Na pesquisa conduzida por Tassou et al. (2004), os pesquisadores explicam a ocorrência de Salmonella enterica pelo fácil desenvolvimento do patógeno em frutos do mar. Este fundamento justificaria a presença da bactéria nestes tipos de alimentos, inclusive naqueles já prontos para o consumo, trazendo um fato de grande importância aos consumidores.

Com relação aos manipuladores de alimentos, em 2004 ocorreu uma toxi-infecção alimentar em São Paulo, acometendo $51 \%$ dos participantes de um evento. A Salmonella enterica subsp. enterica serovar Typhimurium foi considerada a causadora do problema. Não foi determinada como ocorreu a contaminação, mas a identificação de um manipulador portador assintomático da bactéria confirma a hipótese da contaminação no preparo (Silva et al., 2004).

Já na pesquisa realizada por Almeida (1995), em mãos de manipuladores, a Salmonella spp. não foi isolada, apresentando resultado diferente do presente estudo.

\section{Conclusão}

A partir dos dados conclui-se que a constatação de Salmonella spp. nas amostras testadas indica a ocorrência de falhas nos procedimentos de elaboração do "sashimi".

RI oferecia "sashimis" com maior garantia de inocuidade quando comparado com RII. 
Embora as condições estruturais de RII levantassem a hipótese de que os melhores resultados obtidos seriam neste estabelecimento, falhas em quaisquer das etapas do processamento do alimento, principalmente na aquisição da matéria-prima, explicam o resultado bacteriológico das amostras testadas em RII.
Este experimento permite sugerir a necessidade de maiores estudos da ocorrência de patógenos em alimentos consumidos in natura, de acordo com os diferentes hábitos de consumo de alimentos no país, visto que este é um tema de grande relevância à saúde pública.

\section{Agradecimentos}

Ao Programa de Pós-graduação em Medicina Veterinária da Universidade Federal Fluminense.

À CAPES, pela bolsa de Mestrado concedida à aluna Lícia Cristina Miranda Malavota.

\section{Referências}

ADESIYUN, A.A. Prevalence of Listeria spp., Campylobacterspp., Salmonella spp., Yersinia spp. and toxigenic Escerichia colion meat and seafood in Trinidad. Food Microbiology, n.10, p. 395-403. 1993. ALMEIDA,R.C.C.; KUAYE,A.Y.; SERRANO,A.M. et al. Avaliação e controle da qualidade microbiológica de mãos de manipuladores de alimentos. Rev. Saúde Pública. [online]. v. 29, n. 4, Ago. 1995, [citado 12 Maio 2006], p.290-294. Disponível em: <http://www.scielo.br/ scielo.php?script=sci_arttext\&pid=S0034-89101995000400006\& Ing=pt\&nrm=iso >. ISSN̄ 0034-8910.

ANDRADE, N.J. Biofilmes: métodos usados para detecção em superfície e avaliação de sua remoção. CONGRESSO LATINO-AMERICANO DE MICROBIOLOGIA E HIGIENE DE ALIMENTOS, 5., Águas de Lindóia, São Paulo, Resumos, p. 28. 1998.

ARCHER,R.M.B.; MORETTO,E. Ocorrência de Vibrio parahaemolyticus em mexilhões (Perna perna, Linnaeus, 1758) de banco natural do litoral do município de Palhoça, Santa Catarina, Brasil. Cad. Saúde Pública, v.10, n.3. 1994. Disponível em:<http://www.scielo.br/scielo. php? script=sci_arttext\&pid=S0102-311X1994000300017\& lng=pt\&nrm=iso $>$.Acesso em: 05-ago-2007.

BRASIL. Ministério da Agricultura, Pecuária e Abastecimento, Instrução Normativa $n^{\circ} 62$ de 26 de agosto de 2003. Métodos analíticos oficiais para análises microbiológicas para controle de produtos de origem animal e água - Anexo. Brasília, 2003.

BRASIL. Ministério da Saúde, Agência Nacional de vigilância Sanitária (ANVISA), Resolução - RDC n. 12 de 02/01/2001, Regulamento Técnico sobre os padrões microbiológicos para alimentos. Brasília, 2001.

CHEN,J. Pesquisa de Vibrio parahaemolyticus em atum (Thunnus spp) comercializado na zona sul do município de São Paulo, SP. Faculdade de Medicina Veterinária e Zootecnia. Dissertação (Mestrado). 2004. Disponível em: http://www.teses.usp.br/teses/ disponiveis/10/10134/tde-17062005-122613/.

FAO. Documento Técnico sobre as pescas. Garantia da qualidade dos produtos da pesca: Aspectos da qualidade associados ao pescado, 2003. Diponível em: http://www.fao.org/docrep/003/T1768P/ T1768P03.htm

FEDH(a), Food and Environmental Hygiene Department. Sushi and sashimi generally safe. Edição de 28 de abril de 2000 . Disponível em: http://www.info.gov.hk/gia/general/200004/28/0428192.htm. Acessado em 30-set-2006.

FEDH(b), Food and Environmental Hygiene Department. Risk Assessment Studies Report No. 2 Microbiological Hazards Evaluation SUSHI \& SASHIMI IN HONG KONG, 2000. Disponível em: http:// www.info.gov.hk/gia/general/200004/28/0428192.htm.

FORSYTHE, S.T. Microbiologia da segurança alimentar. Porto Alegre: Artmed, 424 p. 2002.
HERRERA, F.C.; SANTOS, J.A.; OTERO,A.; GARCIA LOPES, M.L.. Occurrence of foodborne pathogenic bacteria in retail prepackaged portions of marine fish in Spain. Journal-of-Applied-Microbiology, v. 100 , n. 3, p. 527-536. 2006.

HOBBS, B.C.; ROBERTS, D. Toxiinfecções e controle higiênicosanitário de alimentos. 6. ed., São Paulo: Livraria Varela, 375 p., 1999. Traduzido por: Marcelo Arruda Nascimento.

JAY,J.M. Microbiologia de alimentos. 6. ed. Porto Alegre: Artmed, 711 p. 2005.

MARTINS, F.O. Avaliação da qualidade higiênico-sanitária de preparações ("sushi" e "sashimi") à base de pescado cru servidos em bufês na cidade de São Paulo, 142 p. Dissertação (Mestrado)Universidade de São Paulo Faculdade de Saúde Pública, 2006.

MENEZES, F.G.R; SILVA, C.M; CARVALHO, F.C.T; SOUSA, D.B.R; VIEIRA, R.H.S.F. Salmonella e Staphylococcus coagulase positiva em "sushis" e "sashimis" comercializados na cidade de Fortaleza, Ceará, 4 p. 2006,

PEREIRA, C.S.; VIANA, C.M.; RODRIGUES, D.P.. Vibrio parahaemolyticus produtores de urease isolados a partir de ostras (Crassostrea rizophorae) coletadas in natura em restaurantes e mexilhões (Perna perna) de banco natural. Ciênc. Tecnol. Aliment., v. 24, n. 4, 2004. Disponível em: <http://www.scielo.br/scielo.php?script=sci_arttext\& pid=S0101-20612004000400019\&Ing=pt\&nrm=iso >. Acesso em: 5 ago. 2006.

PIGNATO, S.; MARINO, A.M.; EMANUELE, M.C.; IANNOTTA, V.; CARACAPPA, S.; GIAMMANCO, G.. Evaluation of New Culture Media for Rapid Detection and Isolation os Salmonellae in Foods. Applied and Environmental Microbiology, v.61, n.5, p.1996-1999, 1995.

SAAVEDRA, M.J., BRITO, R.D., SOUSA, M. et al. Isolamento de Pasteurella spp. e Vibrio spp. em robalos (Dicentrarchus labrax): susceptibilidade a diferentes grupos de antibióticos. Arq. Bras. Med. Vet. Zootec. [online]. 2004, v. 56, n. 2 [citado 2007-07-02], p. 277279, 2006. Disponível em: <http://www.scielo.br/scielo.php? script $=$ sci_arttext \& pid=S0102-09352004000200022\& lng=pt\&nrm=iso $>$. ISSN 0102-0935.

SANTOS,R.M. Avaliação da qualidade higiênico-sanitária de peixes comercializados em Mercados Municipais da cidade de São Paulo, SP, 96 p. Dissertação (Mestrado)-Universidade de São Paulo Faculdade de Saúde Pública, 2006.

SCHULZ, S.G.; MUELLER,M.; JARK,U.; ETZEL,V.; HORN,D.; FELDHUSEN,F. Food hygienic examination of sushi products and the basic raw material. Archivfuer-Lebensmittelhygiene, v. 54, n. 2, p. 37-41; 35 ref, 2003.

SILVA,C.C., RODRIGUES,M.M., MARTINS,B.R., EDUARDO,M.B. de P., BASSIT,N.P., CÉSAR,M.L.V.S. et al. Toxinfecção Alimentar por Salmonella em São Paulo/SP, Boletim Epidemiológico Paulista, nov; 11. 2004. Disponível em: http://www.cve.saude.sp.gov.br/agencia/ bepa11_salmo.htm. Acessado em: 22 dez. 2007. 
SILVA-JUNIOR,E.A. Manual de controle higiênico-sanitário em alimentos. 4. ed. São Paulo: Varela, 2001.

STANSBY, M.E. Tecnología de la Industria Pesquera. Zaragoza, Espanha: Editorial Acribia, 443 p., 1968.

TASSOU, C.C.; LAMBROPOULOU, K.; NYCHAS, G.J.E.. Effect of Prestorage Treatments ans Storage Conditions on the Survival of Salmonella enteritidis PT4 and Listeria monocytogenes on Fresh Marine and Freshwater Aquaculture fish. Journal of Food Protection, v. 67, n. 1, p. 193-198. 2004.
TAUNAY, A.E.; FERNADES, S.A.; TAVECHIO, A.T.; NEVES, B.C.; DIAS, A.M.G.; IRINO, K. The role of Public Laboratory in the problem of Salmonellosis in São Paulo, Brazil. Rev. Inst. Med. Trop. São Paulo, v. 38, n. 2, p. 119-127, 1996.

WATANABE,E.; KAMADA,Y; HAMADA-SATO,N.. Development of quality evaluation sensor for fish freshness control based on $\mathrm{KI}$ value. Biosens Bioelectron, v. 21, n. 3, p. 534-538, England, 2005. 